\title{
Influence of Knife Geometry on Selected Factors Pertaining to the Delimbing Process
}

\author{
Ján Melicherčík,* Jozef Krilek, Ján Kováč, and Pavol Harvánek \\ Cutting mechanisms and the cutting force are the focus of this article. \\ The cutting force can be determined theoretically or mathematically by \\ statistical analysis. In this work, the cutting speed was compared when \\ changing the diameter of the test wood and when using the three types of \\ angular geometry of delimbing knives. Experimental measurements were \\ conducted on a self-designed experimental pneumatic stand. Empirical \\ relationships and values from the scientific literature were used to \\ determine the input parameters. Based on a regression analysis, \\ conclusions were drawn relative to factors affecting the process of \\ delimbing. The angular geometry of the delimbing knife plays a significant \\ role in the delimbing process. The thicker the knife, the higher the energy \\ consumption in the cutting process and the poorer the quality of the cutting \\ surface of the wood. The quality of chipless separation timber was found \\ to depend on the cutting speed, and the optimal speed was $2.0 \mathrm{~m} \mathrm{~s}^{-1}$.
}

Keywords: Cutting force; Cutting speed; Delimbing knife; Branch diameter

Contact information: The Technical University in Zvolen, The Faculty of Technology, The Department of Environmental and Forestry Machinery, T. G. Masaryka 24, Zvolen 96053 Slovakia;

*Corresponding author: xmelichercikj@tuzvo.sk

\section{INTRODUCTION}

The chipless wood cutting process, as the object of investigation, is characterized by a number of parameters found to be in close correlation with one another. The geometry of the knife and the cutting force have a significant influence in the delimbing process of wood; they affect a large number of factors, as shown in previous studies (Mikleš and Mikleš 2012; Krilek et al. 2018). Delimbing is the technological process in which the tool penetrates the material (wood) and interferes with the interconnection of wood fibers in order to divide it into 2 or more parts (Siklienka et al. 2017). The feeding mechanism of the device consists of a pneumatic cylinder, the primary delimbing knife with different geometric shapes, and a different cutting edge angle. Delimbing is a process that is used to cut branches from the trunk during the tree harvesting process. This process can be described as the chipless cutting of green wood (Spinelli et al. 2010; Hatton et al. 2016). The chipless wood cutting process is a forestry process that is used primarily in machines for delimbing trees. It is a technological process in which a product is produced without the formation of chips (Siklienka et al. 2017). This method of cutting is applied to the cutting heads of multi-operation machines (USA, Canada). The free-body diagram of the work of the wedge knife is shown in Fig. 1. The process of chipless wood cutting, with the help of a branching knife, is carried out across the fibers in the wood. This condition causes an increase in the cutting force acting on the pruning knife. Somewhere it is possible to define this process as force cutting. (Marko 1997). 


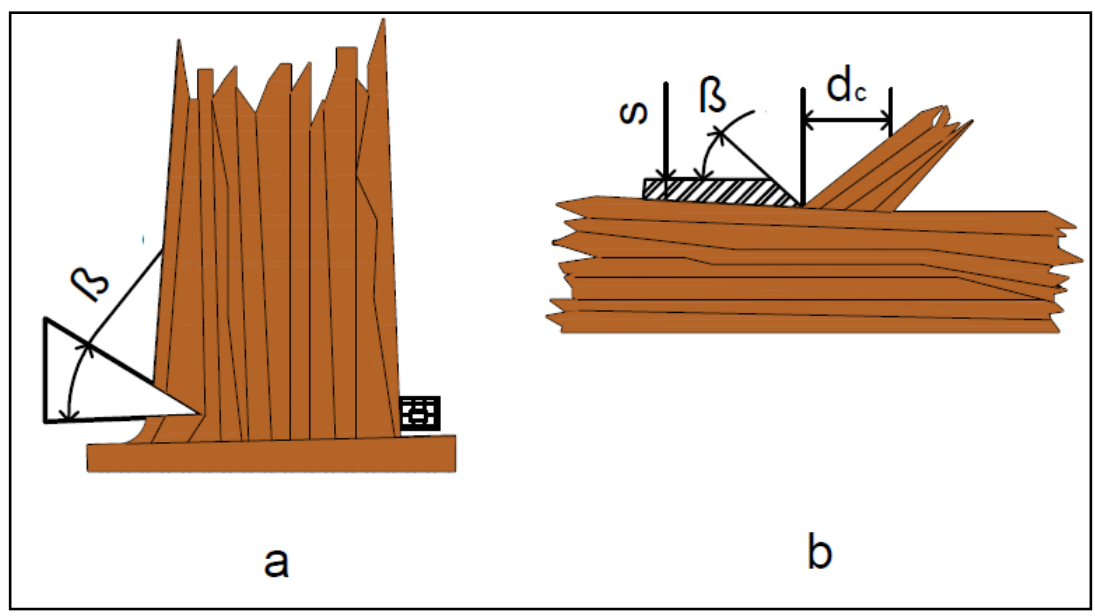

Fig. 1. (a) wood cutting with a wedge knife; and (b) wood cutting with a flat knife (Krilek et al. 2018)

\section{Delimbing Knife}

A delimbing knife is a cutting tool whose design may have different profiles, i.e., the cutting edge shape and the cutting edge. The cutting edge is the part of the cutting wedge that is to be cut and is the intersection of the face and back of the tool with a knife thickness "s". With the cutting edge angle $\beta$ and the back angle $\alpha=0$, the cutting angle is $\delta=\beta$. The results of chipless wood cutting research showed that the cutting force at the entrance of the knife into the wood initially increased linearly and then dropped to zero. The maximum force $F_{\max }$ corresponds to a knife penetration depth of $55 \%$ to $80 \%$ at the cross sectional area. When chipless cutting wood via a wedge knife in a direction that does not correspond to the direction of the wood fibers, considerable cutting forces arise. This results in considerable energy intensity of the cutting process. One of the specific cases of this method is the power cutting of branches, in which knives with a complicated structure are used. The special feature of the knives designed for cutting branches via the force method is a combination of effective cutting with copying ability of knives in the process. The magnitude of the cutting force acting in the direction of the velocity vector is the result of all the components of the force of resistance acting on the different parts of the knife, which forms its cutting profile (forehead, back, and cutting edge), (Kováč 2006; Mikleš and Mikleš 2015).

\section{Forces Acting on the Forehead of a Knife Cutting Branch}

Chipless cutting is characterized in particular by the fact that, up to the moment of removal of the branch from the forehead knife, it penetrates the wood only via the compressing the wood and pushing it out of the cutting zone in a volume equal to that of the protruding portion of the knife. This is illustrated by the fact that a branch that has a long enough length is characterized by major resistance to shearing along the fibers, and therefore the vertical force $F_{\mathrm{Q} 1}$ is not able to overcome this resistance. Therefore, chips are not formed, and the branch subsequently observed a characteristic decrease in cutting resistance. The cutting resistance is constantly increasing, reaching the maximum at the moment when the over-cut branch begins to separate from the forehead knife, after which the opposite process takes place. The nature of the growth and decrease of the cutting resistance must ideally be the same. It follows that the maximum force acting from the wood on the forehead of the knife must be counted out based on the condition of energy 
consumption for pressing the wood. Here the authors assume that the relative pressure, caused by the cut-off branch on the forehead of the knife is in direct dependence of the volume of the wood extruded by the forehead in the cutting process.

The measuring pressure on the entire area in contact with the forehead knife being evenly distributed is most likely to cause chipless cutting. The principle is that in the given method, the over-cut part of the branch does not leave the forehead knife but is attached to it until the conditions are maintained and the relationship applies, as shown in Eq. 1,

$$
F_{Q 1(a-z)} \leq \frac{1}{32} \cdot \pi \cdot \cdot(a-z)^{2} \cdot b \cdot \sigma_{O H}[N]
$$

where $F_{\mathrm{Q} 1}$ is the pressure of the wood $(\mathrm{N}), a$ is the longer axis slit branch $(\mathrm{mm}), z$ is the depth of the knife penetration (mm), $b$ is the shorter axis slit branch $(\mathrm{mm})$, and $\sigma_{\mathrm{OH}}$ is the timber strength of the branch along the fibers $(\mathrm{MPa})$.

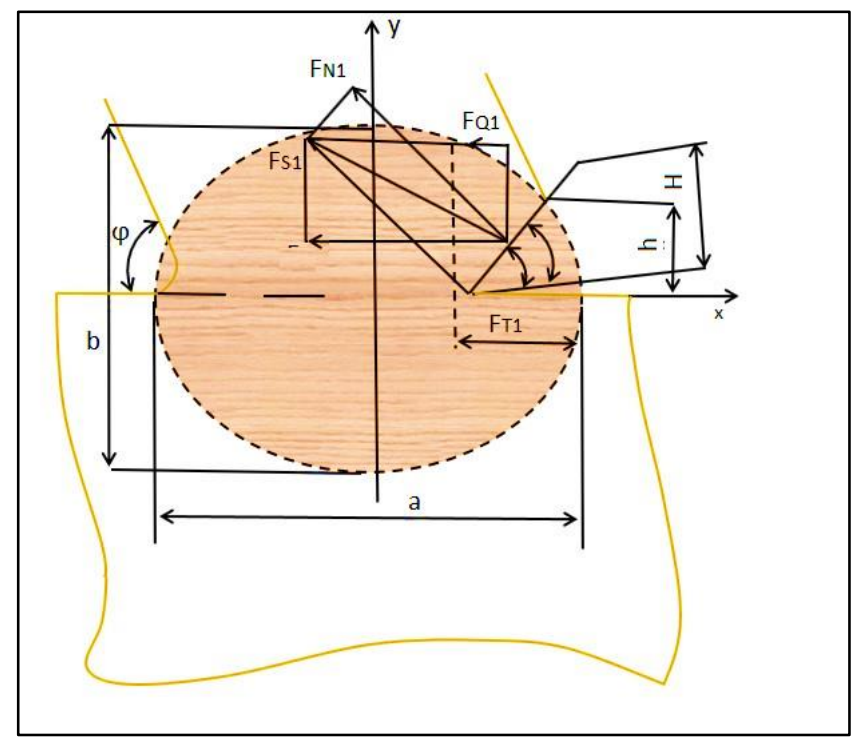

Fig. 2. Forces acting on the front of the knife (Mikleš and Mikleš 2015)

When calculating the forces $F_{\mathrm{S} 1}, F_{\mathrm{Q} 1}$, and $F_{\mathrm{P} 1}$, the deformation is caused by the pressing of the front edge of the knife into the wood. When this occurs, the normal force $\mathrm{F}_{\mathrm{N} 1}$, acting on the forehead of the knife, can be determined from the following relationship, as shown in Eq. 2,

$$
F_{N 1}=q \cdot V_{1}
$$

where $q$ is the specific compression force, per unit of volume of the compressed wood $\left(\mathrm{N} \cdot \mathrm{mm}^{-3}\right)$, and $V_{l}$ is the volume of the wood, knife - crush out $\left(\mathrm{mm}^{3}\right)$.

The resultant force $F_{S 1}$ is obtained as the geometric sum of the forces $F_{N}$ and $F_{1}$ as shown in Eq. 3,

$$
F_{S 1}=q \cdot V_{1} \cdot \sqrt{1+f_{1}^{2}}, N
$$

where $V_{l}$ is the volume of the wood, knife - crush out $\left(\mathrm{mm}^{3}\right), f_{l}$ is the coefficient of friction between the knife and the tree trunk, and $F_{S 1}$ is the resultant force $(\mathrm{N})$.

These values can be applied to Eqs. 4 and 5,

$$
F_{P 1}=F_{S 1} \cdot \sin \left(\delta+\operatorname{arctg} f_{1}\right), N
$$




$$
F_{Q 1}=F_{S 1} \cdot \cos \left(\delta+\operatorname{arctg} f_{1}\right), N
$$

where $F_{P 1}$ is the pressure force $(\mathrm{N})$.

The maximum value of the $F_{R \max }$ cutting force, according to Mikleš (2009) and Hatton et al. (2015), is directly proportional to the square diameter of the "dc" of the cut branch in the bark, as shown in Eq. 6,

$$
F_{\text {Rmax }}=a_{1} \cdot d_{c}^{2}, N
$$

where $a_{l}$ is the coefficient of proportionality, which is dependent on the parameters of the knife, the wood, and the angle of the ingrowth of the branches. This relationship shows that $F_{\text {Rmax }}$ is directly proportional to the cutting surface of branch $S$, as shown in Eq. 7,

$$
F_{\text {Rmax }}=k \cdot S, N
$$

where $k$ equals $\mathrm{F}_{\mathrm{spMAX}}$, which is the proportionality ratio corresponding to the maximum nominal cutting force, which includes the influence of the geometric characteristics of the knife $\left(\mathrm{N} \cdot \mathrm{mm}^{-2}\right)$, and $S$ is the cutting surface of the branch $\left(\mathrm{mm}^{-2}\right)$.

\section{EXPERIMENTAL}

\section{Materials}

This study deals with the comparison of various cutting speeds with respect to the cutting resistance of different delimbing knife geometries. To analyze these different geometries, a special device was built to allow the cutting process to be monitored in laboratory conditions and to measure the cutting forces, which results in recording the energy intensity of the delimbing process. The authors experimented with a pneumatic cylinder. For evaluating the delimbing process, knives with different geometric parameters were used (Table 1). The geometry of the cutting wedge delimbing knife is shown in Fig. 3. The purpose of this paper was to determine the optimal geometry of the knife. Under the same cutting conditions (a delimbing speed of $4 \mathrm{~cm} \cdot \mathrm{s}^{-1}$ ), the maximum cutting force was determined (or measured cutting force).

The experimental measurements were carried out by professional employees of the school forestry company. Wood sampling took place in the course of a logging operation in the forest. The samples were always brought on the day of the experimental measurement, and during the measurement they were stored in an open hangar to maintain the necessary conditions and properties of the wood. The moisture content of the samples was measured by the gravimetric method, always before the start of the experimental measurements. The diameters of the sampling woods used in the experiment were from 10 to $55 \mathrm{~mm}$. A larger diameter sample was inserted into the experimental stand, from which the delimbing branch is based. When measuring a change in the type debranching blade, 27 specimens were studied. The number of specimens was determined by a basic statistical set.

For chipless wood cutting applications in woodland harvesting, further refinement of the cutting tool was necessary. The incompleteness of the design of the cutting tool and the cutting mechanism did not allow for a good cutting surface, especially when cutting frozen wood (in the splitting process wood is shredded and longitudinal cracks emerge from the forehead), and also causes large cutting forces, which cause considerable load on the whole mechanism. 
The theory of chipless wood cutting processes is based on analysis of works by foreign authors (Gerasimov et al. 2012; Hatton et al. 2015; Orlowski et al. 2018) and the author's previous research (Kováč and Alexi 2004; Krilek et al. 2018). That work involved an analysis to determine the impact of various parameters on cutting, and found that the parameter with the greatest impact on the cutting resistance upon entering the wood was the thickness of the knife $(s)$. The greater the thickness of the knife, the higher the energy consumption in the delimbing process and the worse the quality of the cutting surface. Therefore, a reduction in the thickness of the knife can cause a significant impact in terms of tool optimization. For the laboratory pruning tests, 3 knives with a constant thickness ( $s$ $=15 \mathrm{~mm}$ ), the geometry of these knives was the most appropriate according to the results of the initial chipless separation measurements. The effective cutting edge width for all knives was $130 \mathrm{~mm}$. The tool steel DIN C45W was used for the production of the test knives. All knives were hardened to a hardness of $52 \mathrm{HRC}$ to $56 \mathrm{HRC}$ and were machined to a surface roughness of $R_{a}=0.8 \mu \mathrm{m}$. The technical parameters of the blades are shown in Table 2.

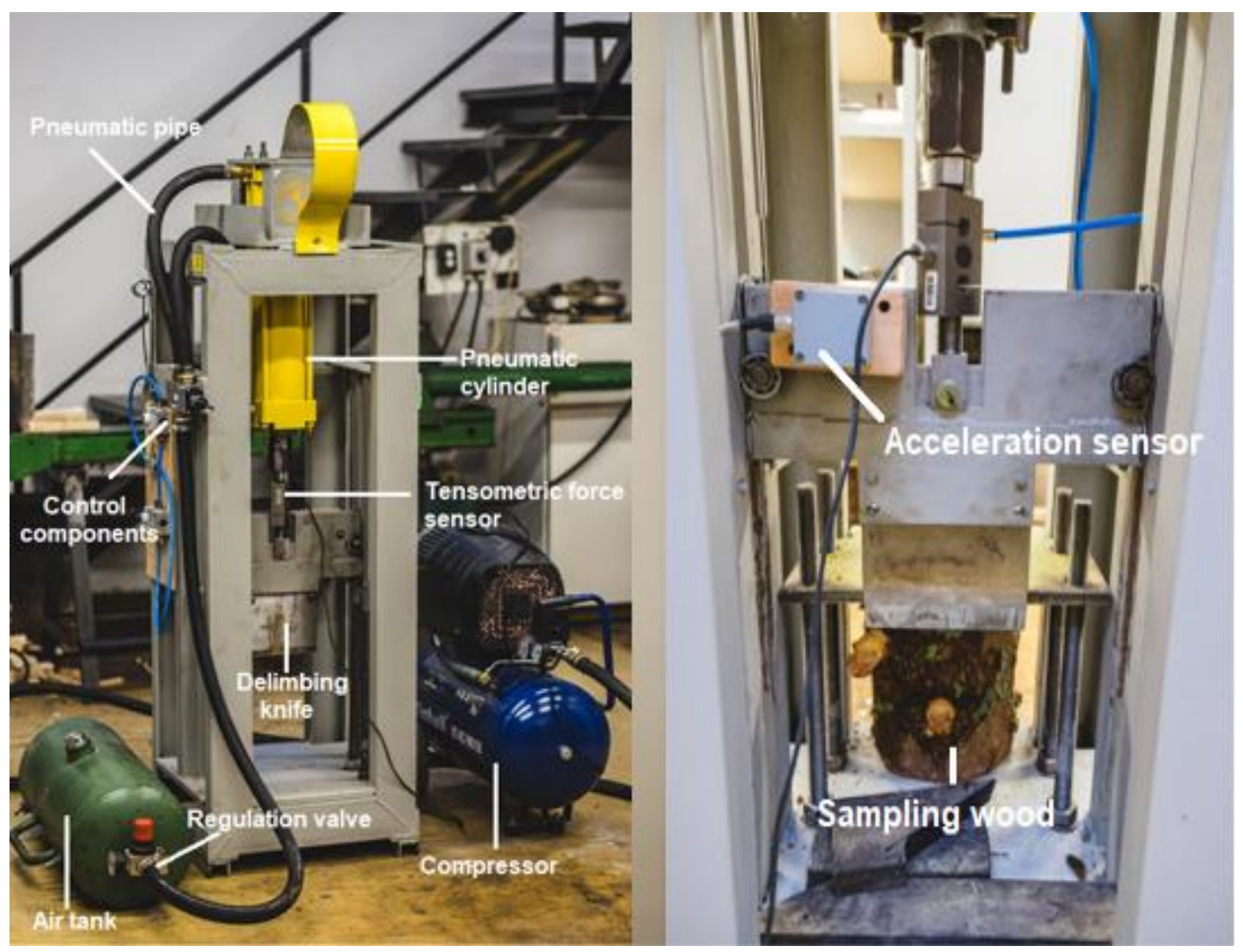

Fig. 3. Experimental device for testing delimbing knives

The experimental equipment was constructed of profiled steel and shaped elements by means of welded joints. The device had dimensions of 1404 x $500 \mathrm{~mm}$, and the branching knife was $400 \mathrm{~mm}$ away from the sample material. The air tank was located on a profile stand, which included a barometer, by which to monitor the air pressure and a pressure reducing valve to adjust the air flow in the system. A pneumatic double-acting cylinder was mounted by screws, with parameters according to ISO 6431. The HBM S9 strain gauge was located on the piston rod of the cylinder by means of the proposed 
fastening jigs. Starting the double acting cylinder provided movement of the pneumatic actuator, which was provided with a check valve and a silencer. The sensor was powered by connecting cables to the Quantum MX 840 measuring unit, which was an 8-channel measuring control panel. The advantage of the measuring unit is compatibility with HBM devices. The cutting device consisted of a flat delimbing knife, which was located on the piston rod and was detected by a pin. After the piston rod is extended, the knife moves towards the wood sample, while there is a transverse division of the wood - delimbing. The sample material was secured against ejection by a pressure cylinder, which was controlled by a separate pneumatic control unit, which consisted of a pneumatic actuator, a throttle valve, a trigger valve, and an exhaust valve at the outlet of the pressure cylinder.

Spruce (Picea excelsa) was used for the experimental measurements, and the chosen wood samples had the maximum specific cutting resistance that was processed. The delimbing branches of fresh spruce branches had a moisture content of $40 \%$ to $70 \%$. Individual measurements were carried out via pneumatic measuring; the primary part the measuring device consisted of a pneumatic cylinder on which the authors fastened the selected delimbing knives, according to Table 2.

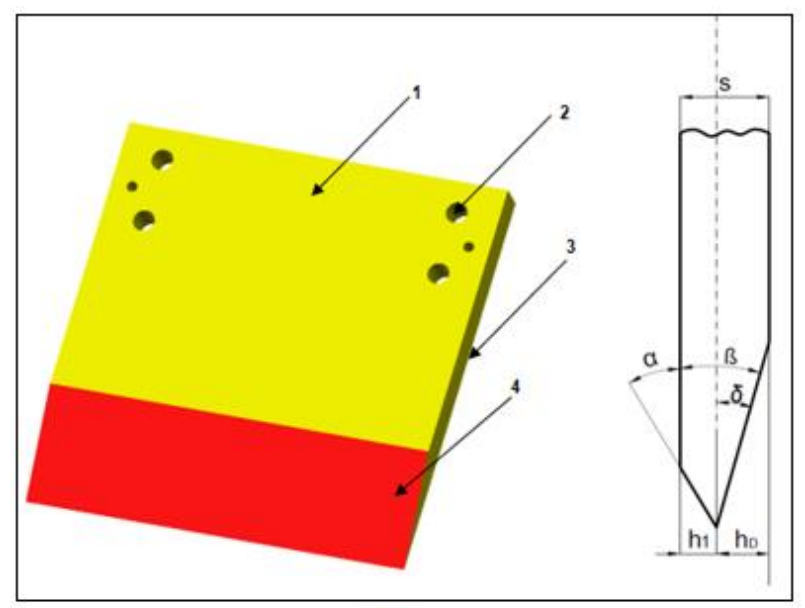

a

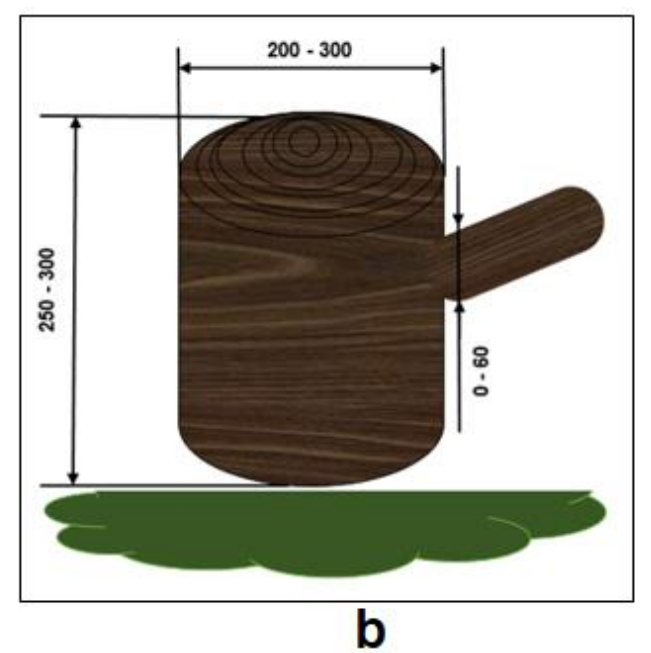

Fig. 4. a.) The geometry of the cutting wedge delimbing knife ( $s$ is the thickness of the knife; $\alpha$ is the angle of the knife; $\delta$ is the cutting angle; $h_{1}$ is the depth the knife penetrates the wood; and $h_{D}$ is the thickness of the cut layer) b.) Sampling trees with the average groups used in the experiment

Table 2. Technical Parameters of the Knives Intended for Experimental Tests

\begin{tabular}{|c|c|c|c|}
\hline $\begin{array}{c}\text { Knife } \\
\text { Number }\end{array}$ & $\begin{array}{c}\text { Cutting Angle } \\
(\delta)\left({ }^{\circ}\right)\end{array}$ & $\begin{array}{c}\text { Back Angle of } \\
\text { Knife }(\alpha)\left(^{\circ}\right)\end{array}$ & $\begin{array}{c}\text { Knife Thickness } \\
(s)(\mathrm{mm})\end{array}$ \\
\hline 1 & 20 & 7 & 15 \\
\hline 2 & 15 & 4 & 15 \\
\hline 3 & 20 & 4 & 15 \\
\hline
\end{tabular}

For the sake of evaluation, the authors compiled a measurement chain from individual sensors. To measure the speed, the authors used a single axis SA I/L acceleration sensor, which measured the acceleration of the knife for a certain time unit, which allows for the calculation of the delimbing speed after conversion. The growth of the HBM Force sensor pressure transducer was within a pressure range of 25 to $60 \mathrm{MPa}$. The process and the individual measurement results were displayed using Conmes Spider (version8) from 
HBM. The experimental delimbing measurements investigated the maximum cutting force and speed relative to the cutting resistance. The tested cutting knife speeds were 1.5, 2.0, and $2.5{\mathrm{~m} . \mathrm{s}^{-}}^{1}$, with three different knives (the knife parameters are shown in Table 2). The relative moisture content of the samples ranged from $21 \%$ to $46 \%$. Basic statistical characteristics were performed in the STATISTICA statistical program (STATISTICA12 software, TIBCO Software Inc., Palo Alto, CA, USA), and the results are shown in Table 3

\section{RESULTS AND DISCUSSION}

The primary goal of this experiment was to compare the cutting speed, with consideration to the cutting resistance and the delimbing knife geometry, via changing the parameters that characterized the cutting process. When cutting a branch at the point of its emergence, the character of the cutting force acting in the direction of the knife displacement is a close-up shape of a triangle with a cut off vertex, with the speed of the cutting knife being a mirror image of the action of the cutting force. When the depth of the cut when the knife enters the branch increases, the cutting force increases linearly and the cutting speed decreases linearly; this pattern coincides with the shape of the typical curve of total wood deformation. The linear dependence of the cutting power and cutting speeds usually changes only at a depth of penetration of the tool equal to approximately $0.5 d_{c}$ (Mikleš and Mikleš 2010), or slightly less than half the branch diameter. The individual laboratory results of the maximum cutting force measurements at different speeds were processed in tabular form with the STATISTICA program.

\section{Statistical Curves of Maximum Cutting Force During the Delimbing Process Using the Delimbing Knives Described in Table 2}

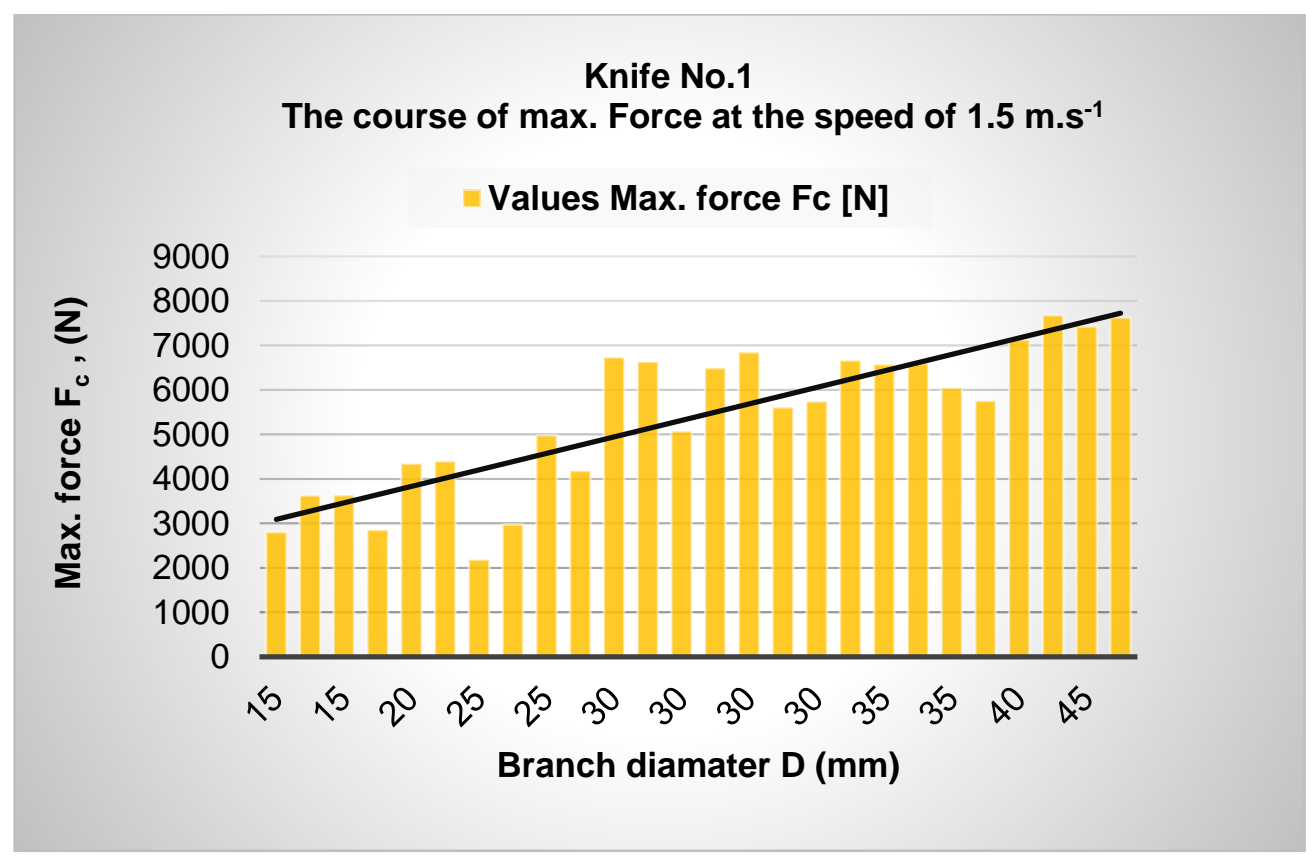

Fig. 5. The maximum cutting force when processing the spruce wood branch at a cutting speed of $1.5 \mathrm{~m} \cdot \mathrm{s}^{-1}$ 


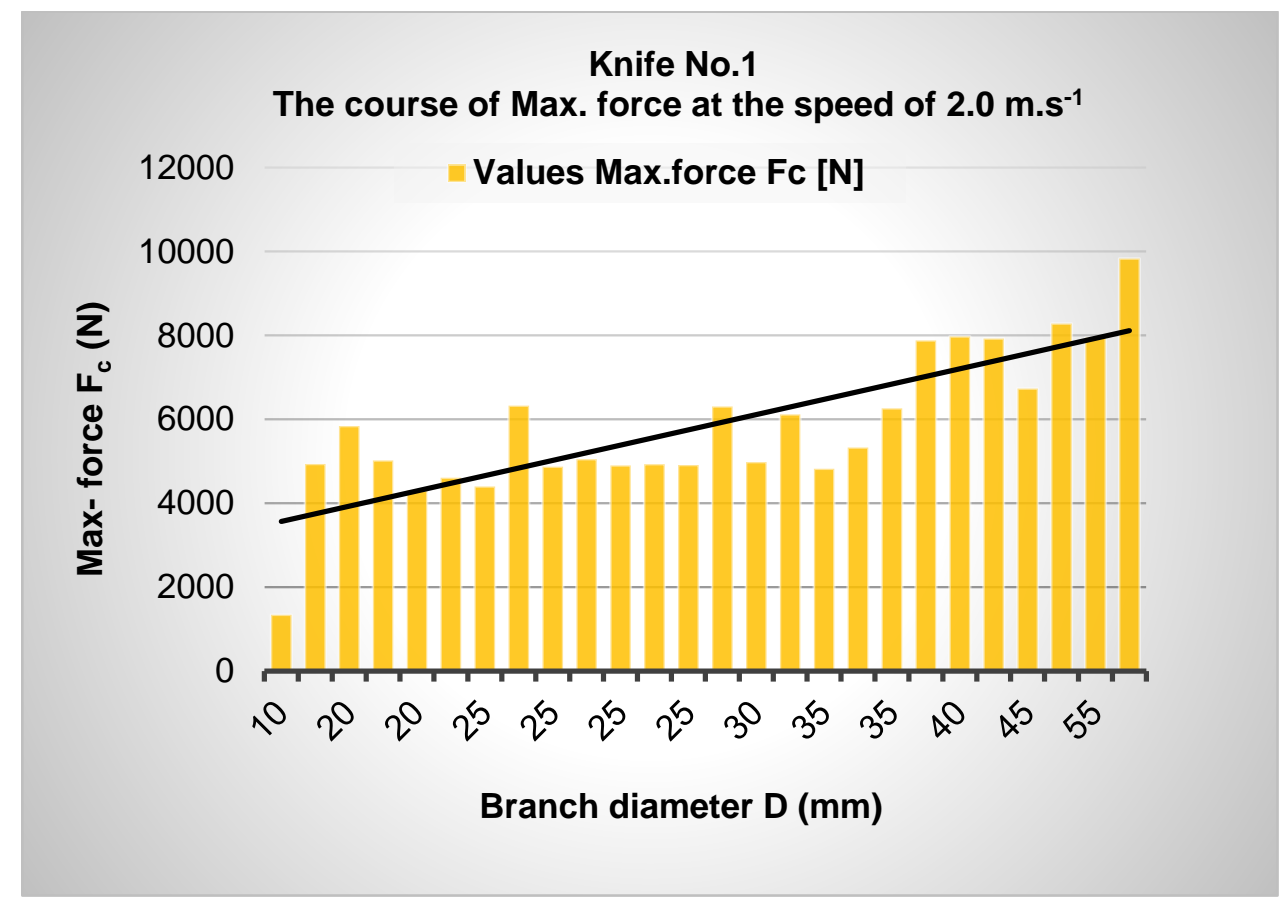

Fig. 6. The maximum cutting force when processing the spruce wood branch at a cutting speed of $2.0 \mathrm{~m} \cdot \mathrm{s}^{-1}$

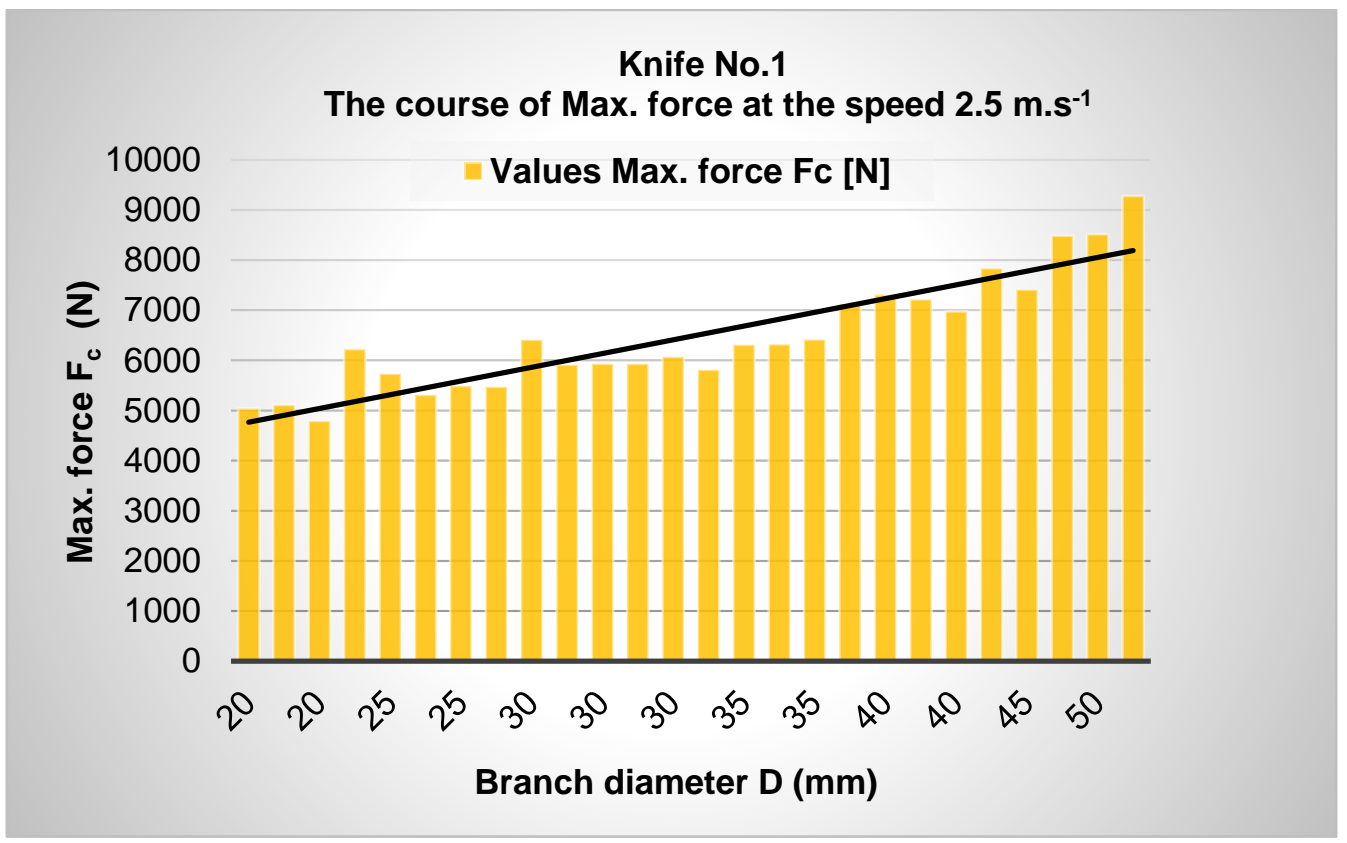

Fig. 7. The maximum cutting force when processing the spruce wood branch at a cutting speed of $2.5 \mathrm{~m} \cdot \mathrm{s}^{-1}$ 


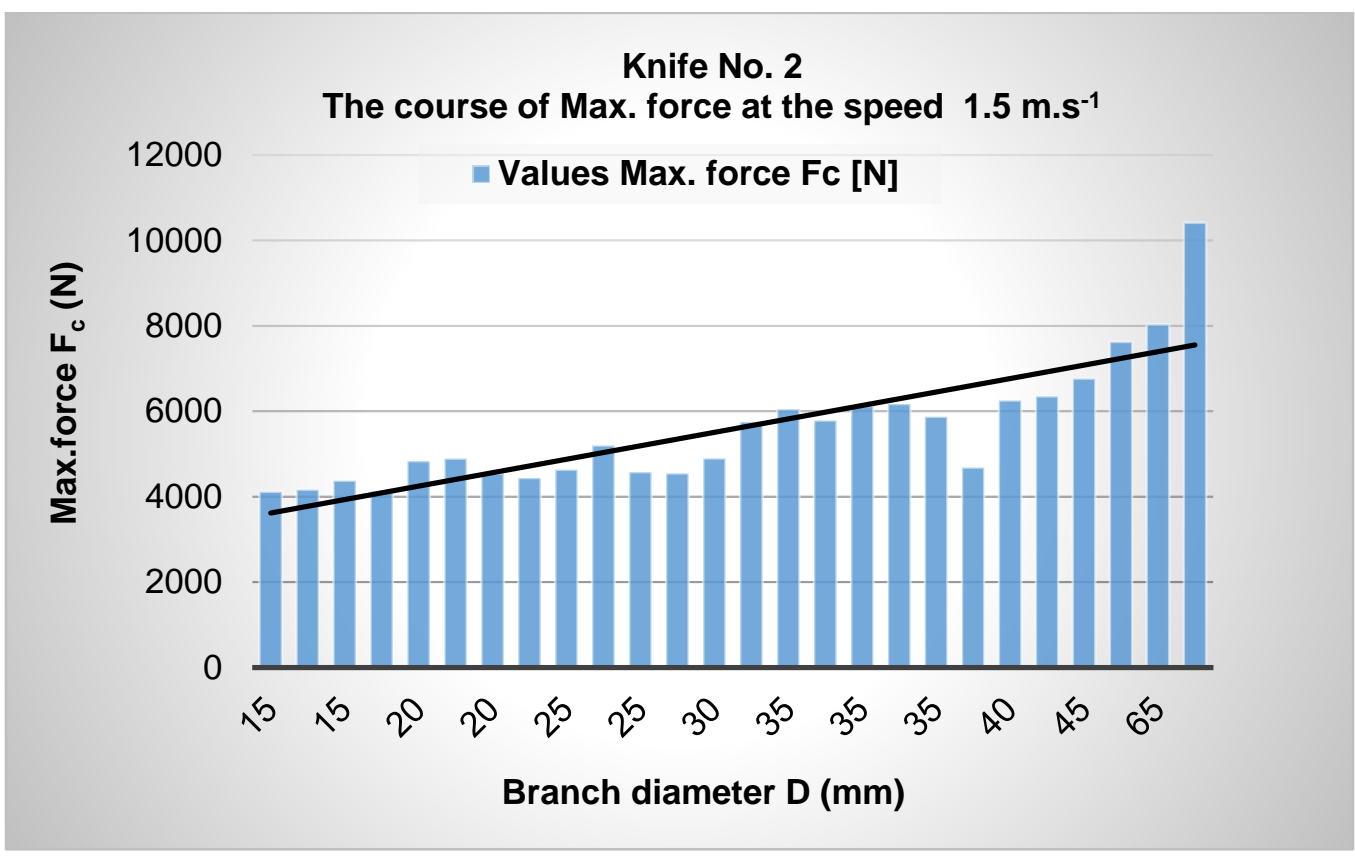

Fig. 8. The maximum cutting force when processing the spruce wood branch at a cutting speed of $1.5 \mathrm{~m} \cdot \mathrm{s}^{-1}$

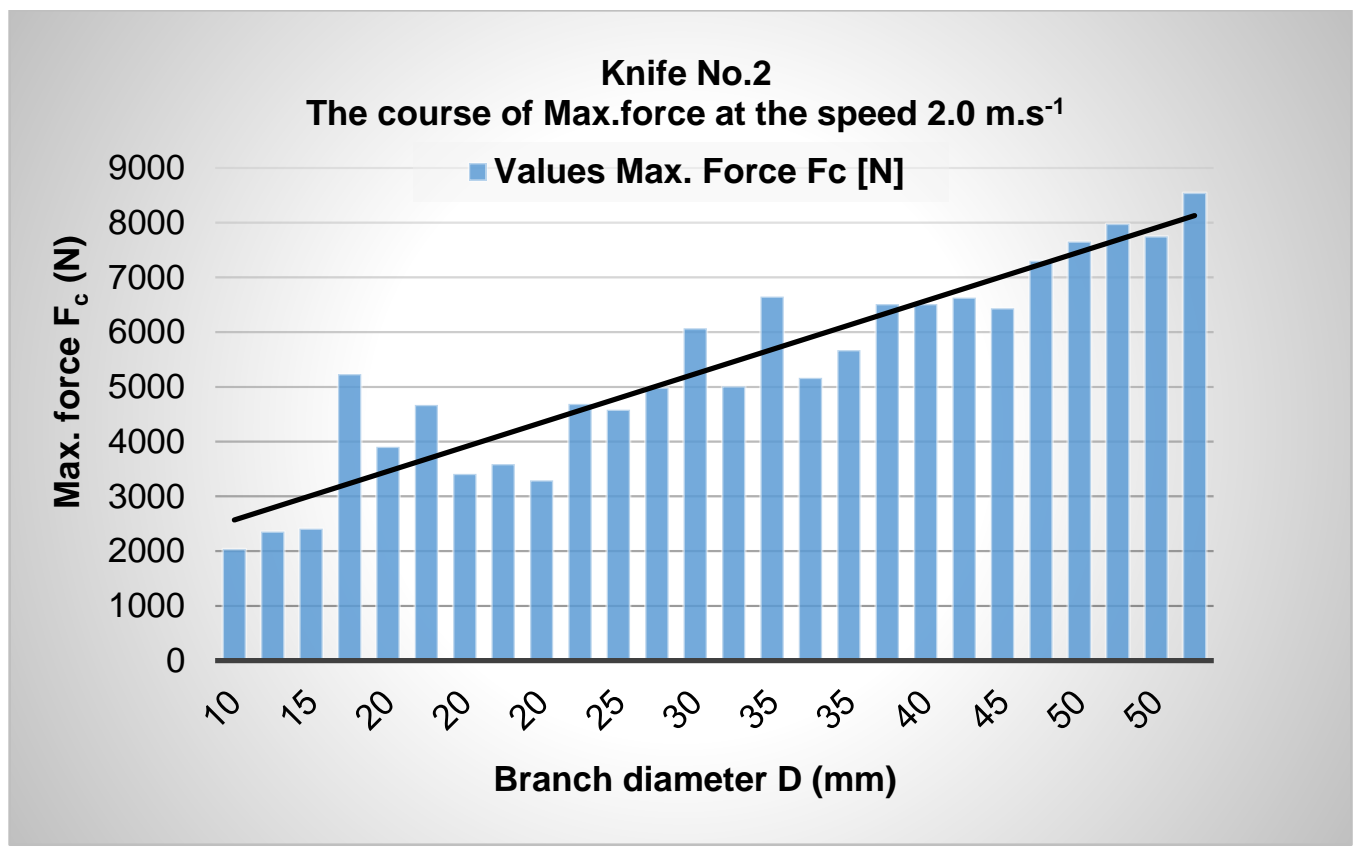

Fig. 9. The maximum cutting force when processing the spruce wood branch at a cutting speed of $2.0 \mathrm{~m} \cdot \mathrm{s}^{-1}$ 


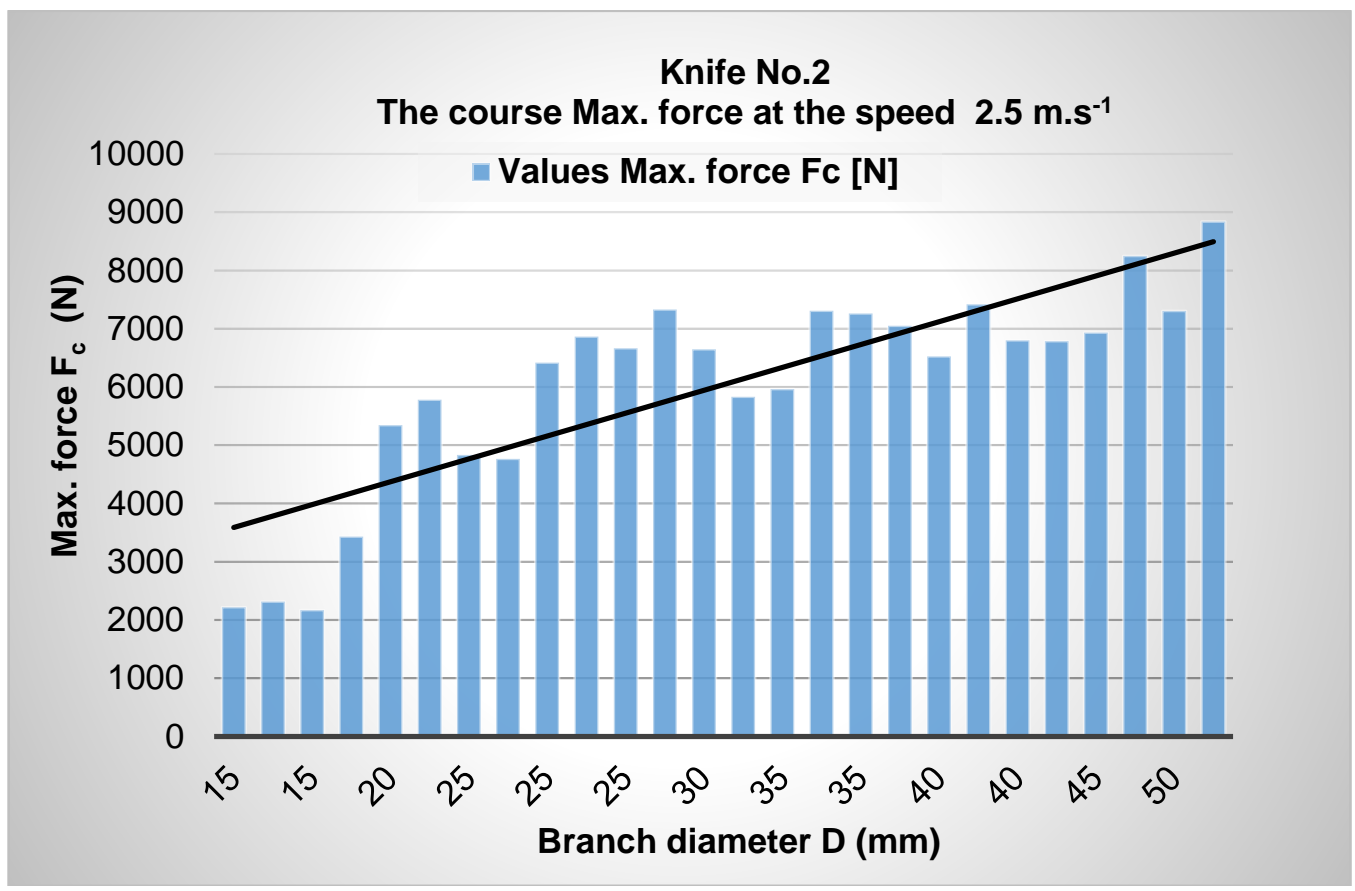

Fig. 10. The maximum cutting force when processing the spruce wood branch at a cutting speed of $2.5 \mathrm{~m} \cdot \mathrm{s}^{-1}$

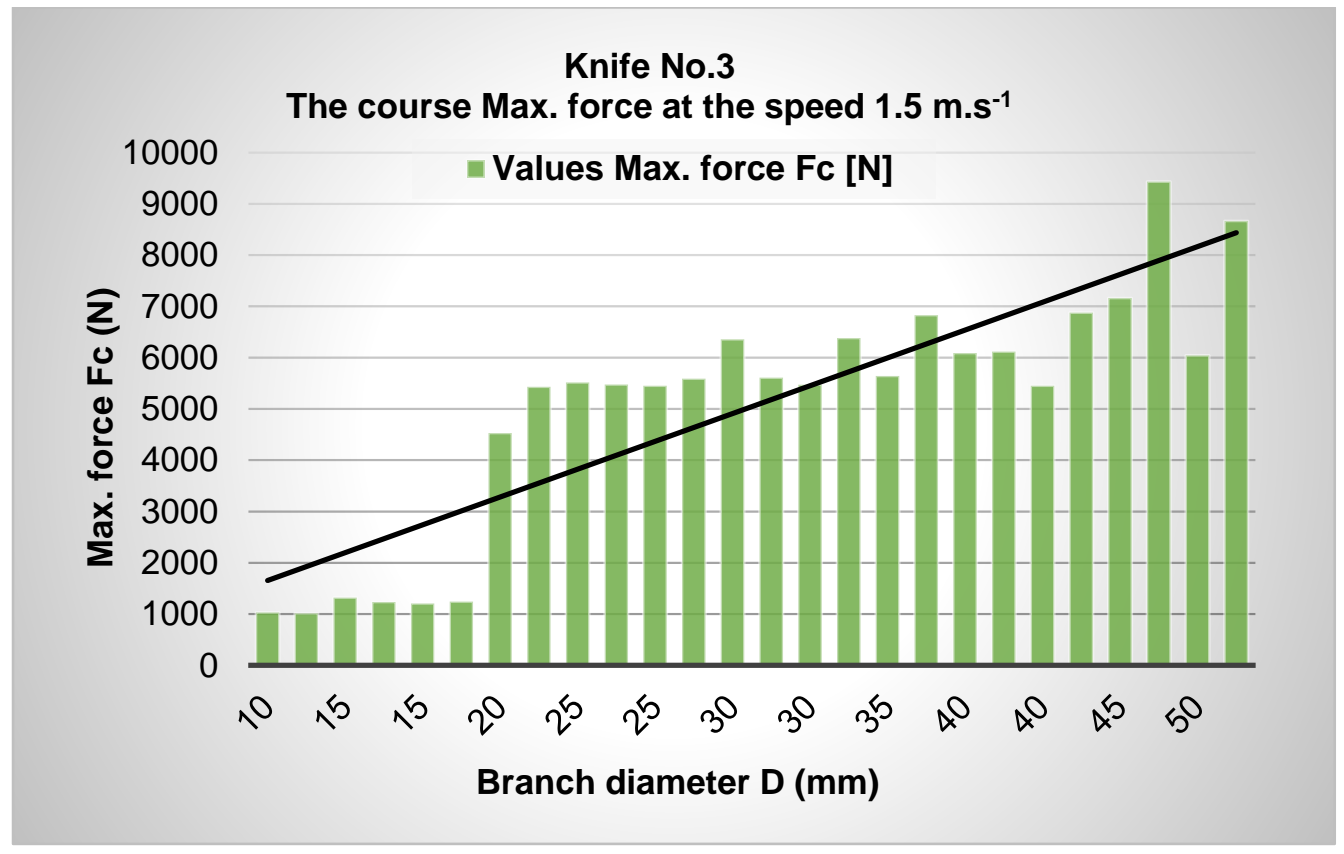

Fig. 11. The maximum cutting force when processing the spruce wood branch at a cutting speed of $1.5 \mathrm{~m} \cdot \mathrm{s}^{-1}$ 


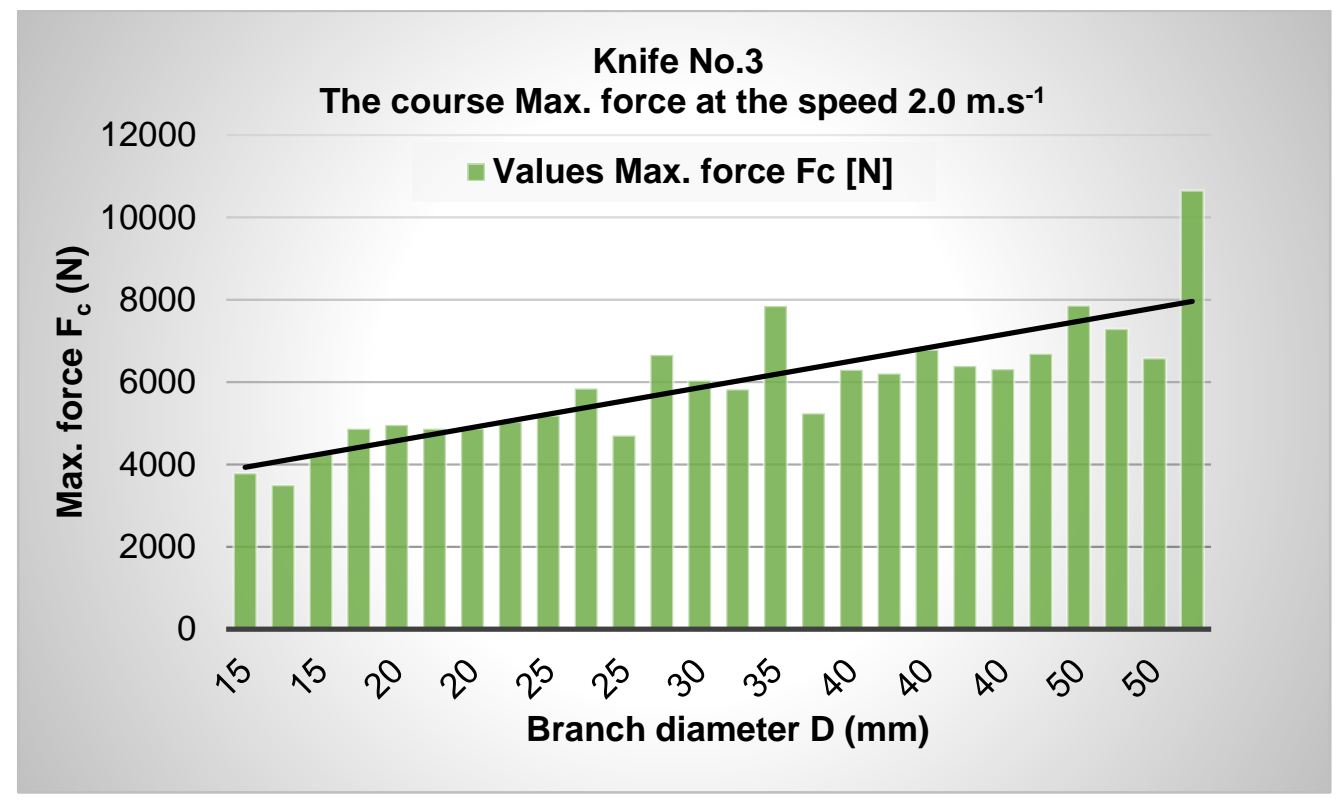

Fig. 12. The maximum cutting force when processing the spruce wood branch at a cutting speed of $2.0 \mathrm{~m} \cdot \mathrm{s}^{-1}$

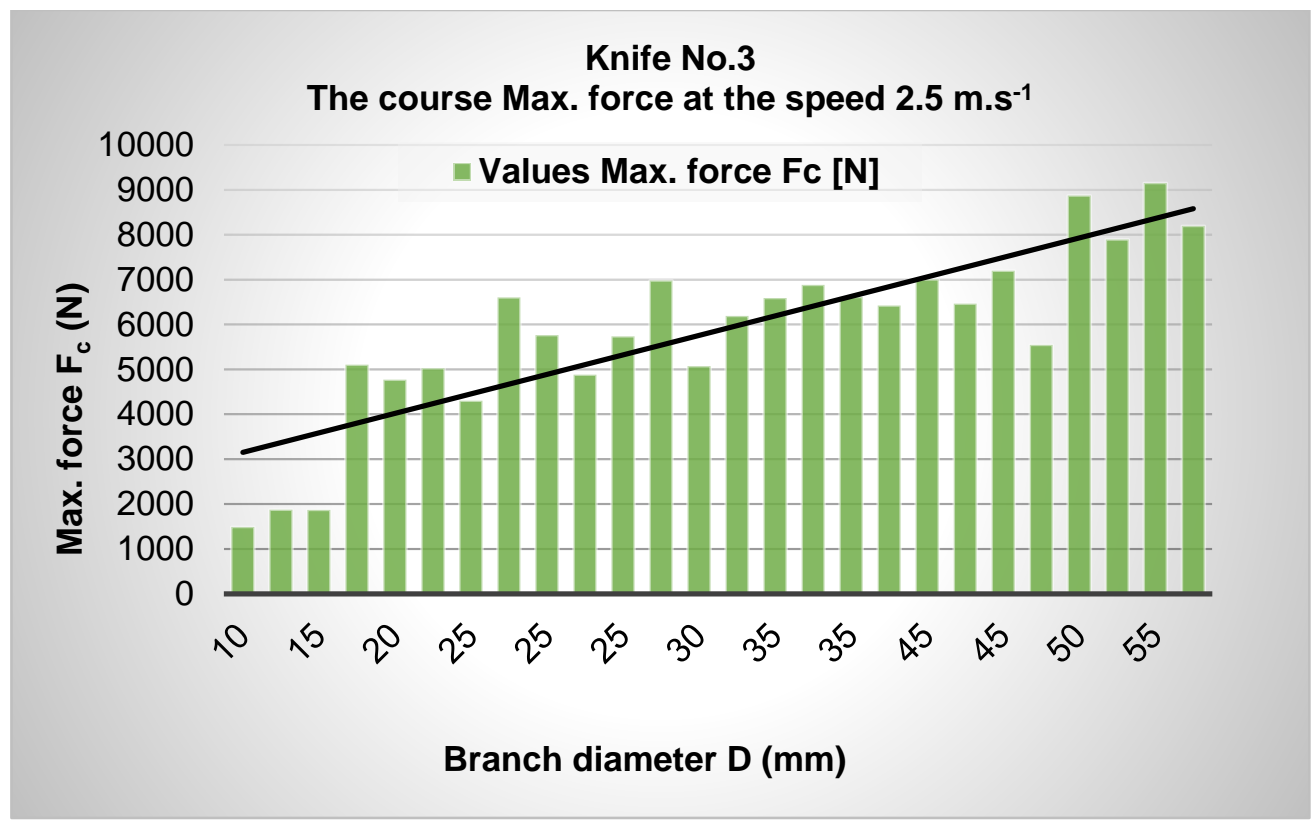

Fig. 13. The maximum cutting force when processing the spruce wood branch at a cutting speed of $2.5 \mathrm{~m} \cdot \mathrm{s}^{-1}$

Covariance multifactor analysis was used to determine the mutual statistical dependence between maximum cutting force (as a dependent variable) and cutting speed. Different knife types and branch diameters (variables in the statistics) represent quantities influenced by another factor to specify the state of statistical significance that was performed for each knife type, knife speed, and branch diameter, as confirmed by the Duncan test. Results of statistical processing of experiments of statistical characteristics, for the dependence of maximum cutting force from the cutting speed, the type of knife and the diameter of the branch are graphically shown in Figs. 5 to 13. 
The intervals of the investigated variables, e.g., maximum cutting force, cutting speed, and branch diameter, as a low energy intensity indicator gave the authors greater insight into the assessment of these parameters in terms of the quality and energy intensity of the chipless woodcutting process. It is clear from the graphs that the plots are linear with an increasing tendency in certain places with a large increment, i.e., where the cutting force of knife sample 3 is constant due to its $20 \mathrm{~mm}$ diameter.

Scientific papers involving the chipless cutting of wood, or delimbing itself, are focused on the overall energy and the quality of the machine or device (Hatton et al. 2015). Such research is important in terms of the operating life, mechanical performance, and economic performance of the machine. However, in order to focus purely on the delimbing mechanism, it is necessary to understand the issues associated with branch cutting from the tree trunk and the factors that affect the life of the knives (McEwan et al. 2016). Industrial damages are caused by different rounding of the wood, which is related to the maintenance of the delimbing machine and, in particular, ensuring a sufficiently sharp cutting edge of the knife (Gerasimov et al. 2012). Delimbing is an expensive wood harvesting operation, which usually reduces the net amount of renewable biomass (Watson et al. 1993). The delimbing mechanism, which is usually a knife, serves to deflect the tree trunk. These are basically hyperbolically shaped knives stored in the collecting head or telescopic shoulder. Delimbing knives should be able to copy the trunk shape as best as possible (Hatton et al. 2015). The cutting resistance and cutting speed of a significant part affects the delimbing process and therefore interferes with the energy intensity of the machine (Orlowski et al. 2014; Pathak et al. 2017). In order to detect the impact of cutting speed, force, and cutting resistance, the Department of Environmental and Forestry Engineering developed and constructed a measuring stent whose functionality was secured by a pneumatic cylinder.

In a report by Siklienka and Šustek (2007) the cutting force, or the required work and performance, was used as the only tool for expressing the cutting edge condition. By assessing the influence of the factors examined on the quality of the deviation from the analyses performed, it was determined that the main quality criterion with the greatest impact on the tear and branching balance was the cutting speed and geometry of the cutting knife, on the basis of which the most favorable cutting speed was $2.0 \mathrm{~m} \cdot \mathrm{s}^{-1}$. At a cutting speed of $1.5 \mathrm{~m} \cdot \mathrm{s}^{-1}$, in terms of the quality of the cut, there were no major branch shoots on the total track path of the branch. The maximum tear value occurred with knife no. 2 (Table 2), which reached $11 \mathrm{~mm}$. At a cutting speed of $2.0 \mathrm{~m} \cdot \mathrm{s}^{-1}$, the cutting surface of the tree branch was smooth enough when compared to a cutting speed of $1.5 \mathrm{~m} . \mathrm{s}^{-1}$ of the residual values of the branches after cutting, ranged from 0 to $5 \mathrm{~mm}$, although max. the balance was up to $8 \mathrm{~mm}$. The greatest influence on the cutting force was the selection of the correct geometry of the delimbing knife, with the optimal geometry of the blade having the following parameters: $\delta=20^{\circ}, \alpha=4^{\circ}, h=2 \mathrm{~mm}, s=15 \mathrm{~mm}$, and $\rho=0.02 \mathrm{~mm}$ (Melicherčík et al. 2020). All effects that acted on the cutting force (with a far greater effect than dullness) made it impossible to compare the results. The relative moisture content of the wood affected the quality of the delimbing process (branch residue and winding). With an increased relative humidity, the cutting speeds, ranging from 1.5 to $2.5 \mathrm{~m} \cdot \mathrm{s}^{-1}$, resulted in visibly better results in terms of tear and branch remnants. This study can provide accurate data that affects the machine life and process quality.

Melicherčík et al. (2021). "Influence of knife geometry," BioResources 16(1), 1757-1771. 1768 


\section{CONCLUSIONS}

1. This article compared the cutting speed with respect to the cutting resistance and the geometry of the blade during the process of cutting chipless wood (delimbing). The primary part of the separating machine was a knife, which was tested with different geometries. Statistical courses precisely define the branching procedure for specific types of knives, which is the basis for conclusions about the respective angular geometry.

2. In terms of the quality and speed of the delimbing knife, it is necessary to choose the most optimal knife geometry with the following parameters: $\delta=20^{\circ}, \alpha=4^{\circ}, h=2$ $\mathrm{mm}, s=15 \mathrm{~mm}$, and $\varrho=0.02 \mathrm{~mm}$ was evaluated by experimental measurements which are statistically evaluated.

3. Under the same cutting conditions, the maximum cutting force $F_{\mathrm{c} \text { max }}=10 \mathrm{kN}$ (or measured cutting force) was determined according to empirical relationships in the area of chipless wood cutting.

4. The thickness of the knife has the greatest influence on the wood processing process. It affects the cutting force, which in the present case ranged from 1.1 to $9.0 \mathrm{kN}$, due to the specified cutting speed and type of wood. The most optimal knife thickness was 15 $\mathrm{mm}$. A greater thickness of the tool leads to higher energy intensity of the cutting process and poorer quality of the cutting surface.

5. The quality of the processed wood and the reduction of energy intensity had the greatest impact of the optimal delimbing speed of $2.0 \mathrm{~m} . \mathrm{s}^{-1}$.

\section{ACKNOWLEDGMENTS}

The authors are grateful for the support of the Scientific Grant Agency of the Ministry of Education, Science, Research, and Sport of the Slovak Republic Project: VEGA 1/0609/20 "Research of the cutting tools at the dendromass processing in agricultural and forestry production."

\section{Symbols}

$\beta$ - cutting angle edge $\left(^{\circ}\right)$

$\delta$ - cutting angle $\left(^{\circ}\right)$

$\alpha$ - back angle $\left(^{\circ}\right)$

$d_{\mathrm{c}}$ - distance of the knife from the cut branch (mm)

$s$ - branch thickness (mm)

$F_{\mathrm{Q} 1}-$ vertical force $(\mathrm{N})$

$\phi$ - angle attachment of the branch the trunk $\left(^{\circ}\right)$

$F_{\mathrm{S} 1}$ - maximum cutting tool force $(\mathrm{N})$

$F_{\mathrm{P} 1 \text { - force for determining the cutting resistance }(\mathrm{N})}$

$Q-$ specific pressure $(\mathrm{Pa})$

$V_{1}$ - volume, determined (bounded) on the area $\left(\mathrm{m}^{3}\right)$

$F_{\text {Rmax - }}$ the cutting force depended on the diameter of the branch $(\mathrm{N})$

$S$ - cutting surface of the branch (mm)

$\sigma_{O H}-$ strength of wood along the fibers (MPa) 


\section{REFERENCES CITED}

Gerasimov, Y., Seliverstov, A., and Syunev, V. (2012). "Industrial round-wood damage and operational efficiency losses associated with the maintenance of a single-grip harvester head model: A case study in Russia," Forests 3(4), 864-880. DOI: 10.3390/f3040864

Hatton, B., Pot, G., Bouzgarrou, B.- C., Gagnol, V., and Gogu, G. (2015). "Experimental determination of delimbing forces and deformations in hardwood harvesting," Croatian Journal of Forest Engineering 36(1), 43-53.

Kováč, J. (2006). Analýza Environmentálnych Aspektov Práce Harvesterových Technológii [Environmental Analysis of Working Aspects in the Harvester Technologies] (VEGA 1/3534/06), Technical University in Zvolen, Zvolen, Slovakia.

Kováč, J., and Alexi, Z. (2004). Analýza hydraulického systému rezacieho mechanizmu harvesterovej hlavice [Analysis of the hydraulic system of the harvester head cutting mechanism] (VEGA 1/9260/02), Technical University in Zvolen, Zvolen, Slovakia.

Krilek, J., Kováč, J., Dvořák, J., and Mikleš, J. (2018). Výskum Rezného Mechanizmu Lesníctve [Research of Cutting Mechanisms in Forestry], Technical University in Zvolen, Zvolen, Slovakia.

McEwan, A., Brink, M., and Spinelli, R. (2016). "Factors affecting the productivity and work quality of chain flail delimbing and debarking," Silva Fennica 51(2), 1-14. DOI: 10.14214/sf.1599

Melicherčík, J., Krilek, J., and Harvánek, P. (2020). "Simulation of stress and strain analysis on a delimbing knife with replaceable cutting edge," BioResources 15(2), 3799-3808. DOI: 10.15376/biores.15.2.3799-3808

Mikleš, J., and Mikleš, M. (2015). "Určenie technických parametrov odvetvovacej hlavice $\mathrm{z}$ hl'adiska tvaru a počtu nožov [Determination of the technical parameters of delimbing head the viewpoint of their number and their shape]," Acta Facultatis Technicae 2015(2), 97-108.

Mikleš, J., and Mikleš, M. (2009). "Teória beztrieskového rezania dreva pre odvetvovanie a lesnú t’ažbu," Acta Facultatis Technicae 2, 155-162.

Mikleš, M., and Mikleš, J. (2010). Teória a Stavba Lesných Strojov I. - Lanové Systémy [Theory and Construction of Forest Machines I.: Rope Systems], Technical University in Zvolen, Zvolen, Slovakia.

Mikleš, M., and Mikleš, J., (2012). “Určovanie posuvnej rýchlosti ret'azovej píly pri spil'ovaní stromu harvestorom [Determination of the rate of chain saw feed during tree felling by a harvester]," Acta Facultatis Technicae 2012(3), 101-106.

Orlowski, K. A., Ochrymiuk, T., and Atkins, A. (2018). "Specific cutting resistance while sawing of wood - The size effect," Forestry and Wood Technology 72, 103-107.

Pathak, A. D., Warghane, R. S., and Deokar, S. U. (2017). "Optimization of cutting parameters in dry turning of AISI A2 tool steel using carbide tool by Taguchi based fuzzy logic," Materials Today: Proceedings 5(2), 5082-5090. DOI:

10.1016/j.matpr.2017.12.087

Siklienka, M., and Šustek, J. (2007). "The influence of the circular saw blade clearance on the unevenness of the worked surface," in: Proceedings of the $2^{\text {nd }}$ International Scientific Conference Woodworking Technique 11-15 September, Zalesina, Croatia, pp. 303-311.

Siklienka, M., Kminiak, R., Šustek, J., and Jankech, A. (2017). Delenie a Obrábanie Dreva [Splitting and Woodworking], Technical University of Zvolen, Zvolen, 
Slovakia.

Spinelli, R., Hartsough, B. R., and Magagnotti, N. (2010). "Productivity standards for harvesters and processors in Italy," Forest Products Journal 60(3), 226-235. DOI: 10.13073/0015-7473-60.3.226

Watson, W. F., Twaddle, A. A., and Hudscon, J. B. (1993). "Review of chain flail delimbing-debarking," Journal of Forest Engineering 4(2), 37-52. DOI: 10.1080/08435243.1993.10702648

Article submitted: October 14, 2020; Peer review completed: December 5, 2020; Revised version received and accepted: January 20, 2021; Published: January 22, 2021.

DOI: $10.15376 /$ biores.16.1.1757-1771 